International Journal of Engineering \& Technology, $7(4.34)(2018) 56-60$
SPC
Website: $w w w . s c i e n c e p u b c o . c o m / i n d e x . p h p / I J E T$
Research paper

\title{
Death Rate Analysis Due to Suicide
}

\author{
Mohd Syaiful Nizam Abu Hassan', Mohd Khairul Amri Kamarudin ${ }^{1,2 *}$, Muhammad Hafiz Md Saad², Noorjima \\ Abd Wahab ${ }^{2}$, Ummi Halimatul Nur Adeni Sabri ${ }^{1}$, Wan Nurkhairunnisa Wan Hashin ${ }^{1}$, Nor Syakinah Wahab ${ }^{1}$, Raja \\ Nur Syazwani Raja Md Yusoh', Nur Amalina Fatehah Yusoff ${ }^{1}$ \\ ${ }^{1}$ Faculty of Applied Social Science, Universiti Sultan Zainal Abidin, Kampus Gong Badak, 21300 Terengganu, Malaysia \\ ${ }^{2}$ East Coast Environmental Research Institute (ESERI), Universiti Sultan Zainal Abidin, Gong Badak Campus, 21300 \\ Kuala Nerus, Terengganu, Malaysia \\ *Corresponding authorE-mail: mkhairulamri@unisza.edu.my
}

\begin{abstract}
Suicide is an act committed by an individual consciously aiming to end or eliminate the life itself. But when their act of suicide failed they were categorized as attempted suicide. This is not a new thing for modern society today. According to official statistics, there are about one million people committed suicide around the world within one year, and this amount does not include those killed by others or those killed in the war. Therefore, the study aims to analyze suicide rates recorded by the five countries with the highest rates of suicide and assess the differences in the frequency of suicide cases between men and women. In addition, this study will identify the methods or methods used to commit suicide and what are the risk factors that cause an individual to decide to end his life. The methods used to commit suicide will also be explained more clearly. Suicide symptoms can be serious in society if preventive measures at the early stage are not taken. This study is expected to help future researchers to find ways to save these unlucky ones from doing something that can harm themselves
\end{abstract}

Keywords: Suicide; suicide attempts; risk factors; highest rate; methods suicide.

\section{Introduction}

Every religion that existed in the world whether Islam, Hinduism or Buddhism banned the act of suicide or deprivation of life itself. Each country has different rates and averages about suicidal cases regardless of culture, age and race. According to the World Health Organization (WHO) it is estimated that around 40 people regardless of status and sex will commit suicide at a times. This makes the total within a year of almost one million people end their life or death due to their own conduct of suicide worldwide [1]. When people fail to think of the best solution to a problem they are facing or overestimated against something they will choose an easy solution by suicide [2].

It is estimated that suicide attempts among women are higher, but mortality rates show that three to four more men are compared to women [3]. The development of an individual is not evolved through the environment but determined by genetic, biological and biological factors [4]. Suicide decisions usually occur suddenly and unexpectedly due to the change of emotion and anxiety. Men are more likely to choose a solution using a more rugged and brutal method without long-suffering unlike women who use less effective ways because they are more likely to think of the various problems and fears that they have in themselves $[5,6]$.

Every born human has their own will in their life program. Everything they do is according to the instincts that act as directions to them [7]. Most countries with the highest rates of suicide are western countries comprising Sri Lanka, Lithuania, Guvana, Mongolia and South Korea. The results showed that only $20 \%$ of individuals did not attempt to commit suicide, while another $80 \%$ had committed suicide and $43 \%$ had more than one suicide attempt [8]. However, other researcher was argue that individuals who want to commit suicide will show signs of depression and will commit suicide attempts first [9]. This means suicide rates may change and increase according to individual intentions. In this context, the subject matter is the analysis of suicide rates that have been listed by the highest state and assessing the difference in suicide that occurs between men and women [10]. Knowing the causes, forms and the frequency of suicide among individuals are the most important elements in this case [11]. So it is possible that prevention is possible and the average analysis of suicide can be done accurately. The majority of suicides committed were by non-Muslims who want to end the torture of life.

The purpose of the study was to identify the population of suicidal tendency rates in five countries that recorded the highest records that is Sri Lanka, Lithuania, Guvana, Mongolia and South Korea. The objectives of this paper are to identify the highest rate and average country in the case of suicide, to identify the difference of rates suicide between men and women, to identify the cause of the occurrence of individual tendencies to commit suicide and to identify the way that individuals use to commit suicide.

\section{Methodology}

The researchers use secondary data obtained from the World Health Organization (WHO) website, World Bank Data and World Population Review. The data collected were analyzed and evaluated, and five countries with the highest suicide rate were selected to be the main subjects. The data is then presented in the form of a graph to facilitate the evaluation process. Allowance references to journals, articles and past studies have also been conducted to obtain more detailed information about the risk fac- 
tors that cause an individual to choose to commit suicide and what methods or means are usually used to commit suicide [12].

\section{Result and Discussion}

\subsection{Identifying the Rate of the Country That Have the Highest Suicidal Case}

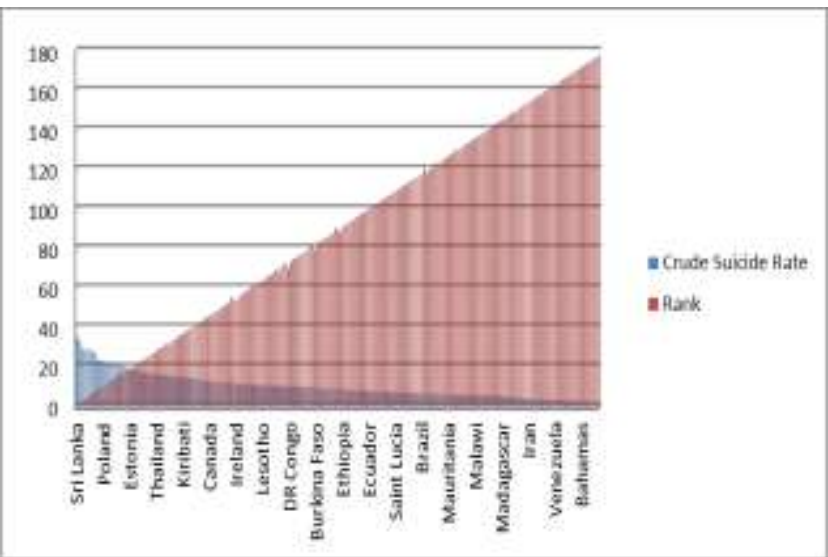

Fig. 1: Crude Suicide Rate by Country 2018

Figure 1 above show the crude suicide rate by country at the year of 2018. According to World Population Review Sri Lanka is the highest country with 35.3 suicides per 100000 followed by the Lithuanian State with 32.7 suicides per 100000 and National the third is Guyana 29 suicides per 100000 . In addition, South Korea and Mongolia with a total of 28.3 suicides per 100000 are also among the five countries with the highest rates of suicide in the world. Then, followed by another country up to rating 177 with a rate of 0 suicides per 100000 by the Antigua and Barbuda State. Sri Lanka is the highest suicide rate of 35.3 per 100000 in 2015 statistics [4]. According to a report published in a seminar by Dr. Neil Fernando, Head of the National Mental Health Institute in September 2011, nearly 4000 people die from suicide in Sri Lanka each year.

Sri Lanka is an island country located in the South Asian Continent (South Asia), Sri Lanka is also known as the Ceylon. Sri Lanka is a country with a population of 22409381 people and the majority ethnic is Sinhala and Buddhism is the official religion of Sri Lanka, about $70.2 \%$ of Sri Lanka people embrace Buddhism.

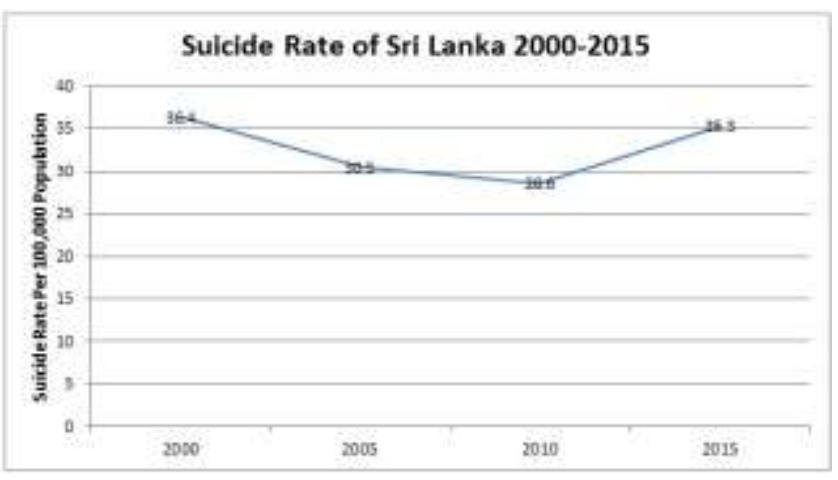

Fig. 2: Suicide Rate of Sri Lanka 2000-2015

Figure 2 shows a record rate of suicide in Sri Lanka in 2000-2015. The rate of suicide in Sri Lanka is unstable that is fluctuations. In 2000, 36400 people were suicidal. In 2005 it fell to 30500 people, while in 2010, 28600 people and 2015 recorded suicide rates in the country rising to 35200 people.

The second highest suicide rate is Lithuania. Social and financial problems in Lithuania are among the key factors behind the high rates of suicide. According to Onute Davidonienė, Director of the National Mental Health Center, the main reason for the heightened suicide case over the last decade was due to the economic and social shift that occurred in this country. This can be attributed to the 1998 Russian economic crisis which extends the phenomenon in Lithuania. Lithuania is a country located in northeastern Europe and $77.2 \%$ of Lithuanians are Catholics.

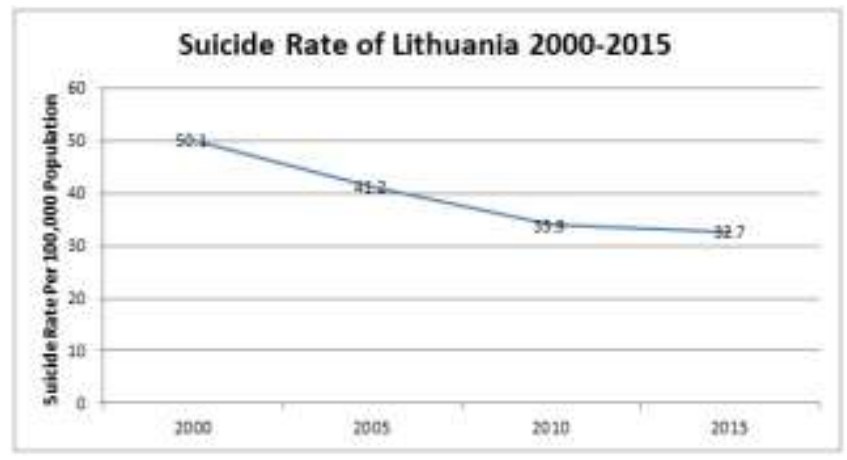

Fig. 3: Suicide Rate of Lithuania 2000-2015

Figure 3 shows the suicide rate of Lithuania in the year of 20002015. With a height of 50.1 suicides per 100000 that is 50100 people reported suicide in 2000 but the suicide case in Lithuania is declining year by year. In 2005 a total of 41.2 suicides per 100 000 was reported and decreased to 33.9 people in 2010 and declined by 1200 in 2015 (32.7). [4].

In addition, Suicide in Guyana is a serious social problem for this State. As many as $40 \%$ of the population of Guyana commit suicide were by poisoning themselves by using agricultural pesticides. Suicide rate in Guyana is 29 per 100000 people in 2015 [4].

Guyana is a country located on the north coast of South America. Guyana is the fourth smallest country in the mainland of South America. While according to the 2002 national census of religious affiliations, the majority of the population of Guyana are Christians and Hindus.

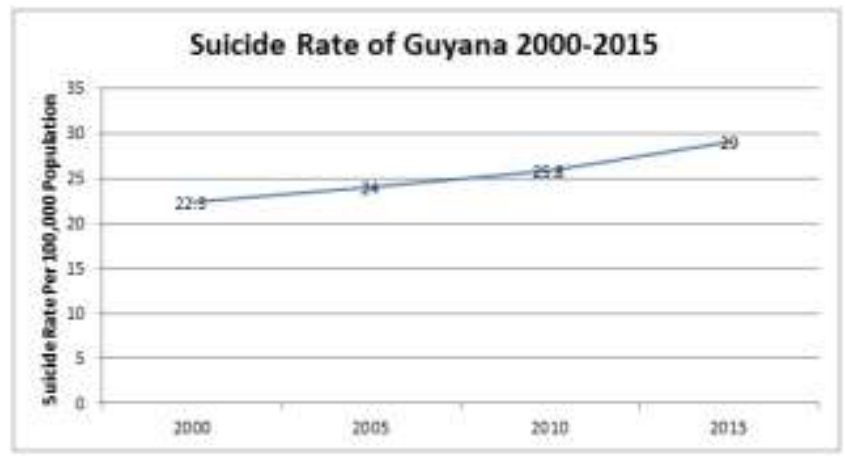

Fig. 4: Suicide Rate of Guyana 2000-2015

Figure 4 records the suicide rate of Guyana in 2000-2015which has been increasing from year to year. In the year of 2000 the World Bank recorded 22.3 suicides per 100000 , then increased to 24000 people in 2010,25800 people in 2010 and continues to increase by 2015 to 29000 suicides per 100000 . This figure 4 clearly shows that the suicide case in Guyana is increasing from year to year.

South Korea has rate of suicide of 32 per 100000 in 2015 statistics [4]. South Korea also records the highest suicide rate for OECD member states. Suicide in South Korea is a serious and widespread problem and most of the people who commit suicide are from the poor elderly. It's a bit of a nuisance to the image of this country as a developed country

South Korea or its official name The Republic of Korea is a sovereign state located in East Asia. It is bordered by the People's Republic of China (Mainland China) to the west, Japan to the east and the Democratic People's Republic of Korea (North Korea) to the north. South Korea is also a developed country with a very high standard of living and is the fourth largest economy in the Asia. South Korea has a population of 50 million people and the majority of South Koreans do not embrace any religion. 


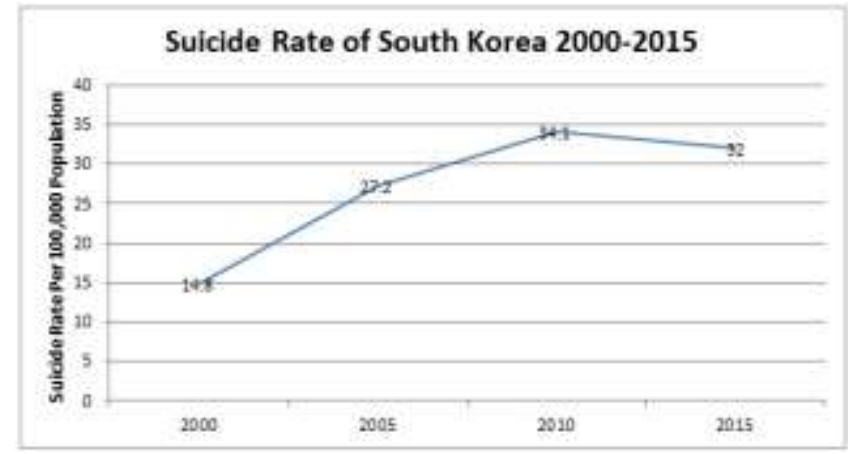

Fig. 5: Suicide Rate of South korea-2015

Figure 5 above records the suicide rate of South Korea in the year of 2000-2015. In 2000, 14,800 people were reported suicide and significantly increased in 2005 with 27200 people and increased to 34100 people in 2010 . However, in 2015 it showed a decline compared to 2010 of 32000 people.

The suicide case in Mongolia is also very serious as Mongolia is ranked fifth in suicide cases per capita worldwide. Mongolia has a high rate of suicide compared to its surrounding nation, that is 28.3 per 100000 people in 2015 statistics [4].

Mongolia is a Republic of the country located in East Asia. The landlocked country is bordered by two countries - the Russian state on the north and China to the south. Mongolia has a total population of 3,068,243 people. The majority of Mongolians are Khalkha Mongol and Buddhists (53\%). Astronomically, Mongolia is located between $41^{\circ}-52^{\circ} \mathrm{N}$ (a small area located at $52^{\circ}$ ) and $87^{\circ}-120^{\circ} \mathrm{E}$

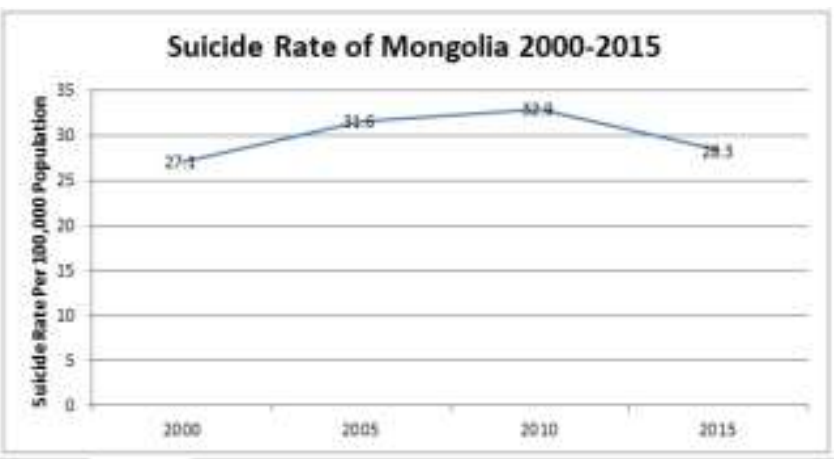

Fig. 6: Suicide Rate of Mongolia 2000-2015

Figure 6 shows the Suicide Rate of Mongolia in the year of 20002015. In 2000 it recorded 27100 (27.1 suicides per 100K) and increased in 2005 to 31.6 suicides per 100000 and increased by 1300 in 2010. As of 2015, World Bank Data showed a decrease of 28.3 suicides per 100 000. Suicide cases in Mongolia are seen to increase from 2000 to 2010 and decline in 2015 .

\subsection{Identifying and Analyzing the Suicide Difference among Men and Women}

Sex suicide rates have proven to be significant. More logical is that women are more often suicidal than men. However, the data proves that it is wrong. Although women are more likely to have suicidal thoughts but data show that the number of men dead with suicide is more frequent than women. This is also known as the gender paradox in suicide.

Generally, suicide deaths occur about 1.8 times more in men than in women in 2008 and 1.7 times in 2015. In the western world, men die from suicide three to four times more often than women (this difference more clearly seen for those 65 years old, with ten times more men than women die from suicide). The tendency for suicide attempts is between two and four times more often in women. The level of suicidal thoughts is unclear, but research shows that suicidal thoughts are more common among women than men, especially under the age of 25 year old. Researchers described the differences between attempts and suicide among men to use more deadly ways to end their lives.

The difference in reported rate of suicide for men and women is the result of the suicide method used by each gender. While women have the tendency to commit suicide, women are more likely to use less deadly methods than men who commit suicide through high mortality, such as poisoning, carbon monoxide poisoning, and firearms. This is clearly contrary to the methods used by women who are more dependent on drug overdoses. Although overdose can be deadly, it does not act immediately and takes time to die and is more likely to be caught before death occurs. In Europe, where gender disagreement is the largest issue, one study found that the most frequent method of suicide between both sexes was to hang out. However, the use of suspension was higher in males $(54.3 \%)$ than females $(35.6 \%)$. The same study found the second most common method is firearms $(9.7 \%)$ for men and drug-poisoning $(24.7 \%)$ for women.

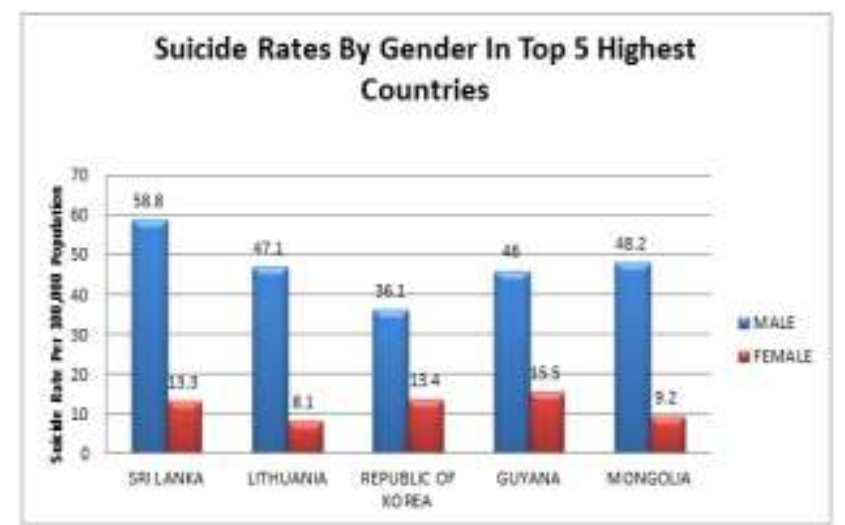

Fig. 7: Suicide Rates by Gender in Top 5 Highest Countries

Figure 7 shows the difference between suicide rates between men and women for Sri Lanka, Lithuania, Republic Of Korea, Guyana and Mongolia. The Sri Lanka state recorded a total of 58.8 suicide men compared to 13.3 women. It shows a difference of 45.5 for both of these genders. While Lithuania showed a difference of 39 , men recorded 47.1 compared to women only 8.1 only. For the Republic of Korea, the number of suicide men was 36.1 compared to women 13.4 with a difference of 22.7. In addition, there are also differences between men and women of the Guyana States. Men recorded 46 compared to women 15.5 with a difference of 30.5 . Lastly is Mongolia, male 48.2 with difference 39 with female 9.2. The five highest suicide states clearly show that death from suicide among men is higher than for women.

\subsection{Identifying the causes of Individual Tendencies for Suicide}

Suicide is often associated with problems arising from desperation, mental, emotional or emotional disturbances, feelings of stress, alcoholism or drug abuse. In addition, the factors that lead to this problem are also caused by financial problems or problems in family relationships. Socio-economic factors such as unemployment, poverty, homelessness also encourage individuals to commit suicide. The lack of support, encouragement and social support services for individual depression is often identified and linked as the main reasons and causes for suicide.

\subsubsection{Mental illness}

Mental illness is a condition that causes depression. The untreated depression is one of the main causes of suicide. Schizophrenia is one of the serious mental illnesses. People and communities usually use words or phrases such as "lunatic", "mentally ill" or "psycho" towards patients with schizophrenia. Schizophrenia is a type of psychological disorder that causes a person to have a problem to distinguish reality. They usually experience delusions or hallucinations. Brain disorders that create uncertain and inexplicable 
feelings that lead to signs such as anxious, inactive, disordered minds and unable to make decisions and act overly. Trauma is a mental disorder that occurs when a person sees or faces any form of violence or extreme cruelty.

\subsubsection{Depression problems through genetics or offspring}

Individuals who experience this problem do not seem to face any experience or adverse event, however they are still under pressure and tend to commit suicide. Therefore, some individuals die by suicide because of depression through genetic factors.

\subsubsection{Negative / bad experience}

This can also refer to depression such as loss or death of loved ones, divorce, or separation with a partner in a relationship. Another factor is the loss of custody rights such as custody of children or that the right of custody decisions is unfair.

\subsubsection{Injury leading to disability / accident}

Paralysis, limb disability resulting in loss or malfunction of one limb will cause a person to feel unable to do any activity or occupation and to continue life as usual, even to trouble others around him. They will feel depressed and then choose to commit suicide.

\subsubsection{Abuse of drugs}

Drugs are something that not only can destroys yourself it can even destroys the future and the life of a human being. Someone who takes drug will be addicted and will not care about the situation and the environment around them including loved ones and immediate family members. Drug abuse here refers to when one takes the drug over the prescribed quantities.

\subsubsection{Unpleasant surroundings}

Someone who goes into problems like poverty, loss of shelter, job, and income, discrimination and bullying is also one of the factors that can cause suicide.

\subsubsection{Victim of circumstance}

Being victimized by physical torture, sexual harassment, rape and genocide is also a factor in suicide. Physical torture that is often the case now cannot be denied. This torture victim does not regard age or category. Usually, women and children are always victims of the situation because they are weak and incapable of fighting.

\subsubsection{Avoid shame or punishment}

Some people also tends to take the easiest path by committing suicide when failing to defend their dignity, they takes the easy way by doing simple acts of suicide.

\subsubsection{Financial loss}

Experience financial losses such as bankruptcy, loss of property, gambling addiction, stock market collapse and debt burden.

\subsubsection{Desperation and challenge from other people}

Loneliness and the feeling of being isolated can also contribute to suicide symptoms. Individuals who do not have many friends prefer to separate themselves from engaging in any activity with others. In addition, the individual is also less communicated and more solitary and some of them cannot control the feelings and the idea of suicide.

\subsubsection{Irrational thinking}

Negative thinking patterns and irrational beliefs can lead to depression and self-esteem problems. It can cause the individual to commit suicide. If this negative mind set can be changed or fixed from the beginning it is likely to help the individual. Among the common-minded patterns encountered and experienced by individuals who want to commit suicide are like the inability to see the right and appropriate choices in problem solving, the negative way of looking and responding to the problem, and not being able to look at every problem clearly and consider all the problems that there are facing is difficult to handle and have no solution.

\subsection{Identifying the Methods that are Uses by Individuals to Commit Suicide}

Suicide is an act of self-destruction in various ways through internal or external. Killing yourself internally is by drinking or putting poison into the limbs or body in purpose of eliminating the life. Most of them who do this are to avoid having any problems. Next, externally suicide can be seen by self-burning or accidentally standing on the rails. Those who are determined to commit suicide usually experience mental illness or mental stress. Without thinking further, they took the easy way to avoid facing the problems. But intentions doesn't approve ways. Although they commit suicide in the interests of others, it is still wrong in any religion including Islam, Christian, Hindu or Jewish. In all religions, it is considered a great sin and had a negative impact to ourselves, society, religion and country. There are several methods of suicide committed by such groups as: -

\subsubsection{Hurting own self with sharp object}

The act of self-injury using sharp objects is nothing new to the self-assassination method committed by a group of people. This method tormenting the individual as it take a long time until the blood comes out of the wounds. In this long process, the perpetrators will feel very painful in the wounded parts throughout the body. The reduced blood causes the body to feel warm and trembling while suffering from severe headaches because blood cannot be transferred to the brain. They are no longer thinking of the pain but their focus is to escape from all the stress. This method can be seen by cutting the pulse or throat until it breaking the vein and produces blood that aims to end their life. Such cases are usually performed by those who experience extreme depression that make them cannot afford to think well. This activity is often done in a quiet place or free from the public's view like the toilet, room or empty house. Useful objects are like glass fragments, sharp knives or metal.

\subsubsection{Hunger strike}

According to Wikipedia, free cyclopedia, hunger strike means refrain from eating and drinking in a period of time until it reaches what their fighting for. They will not eat and just drink to eliminate hunger. This act is usually done by an individual or a group to show their dissatisfaction with an action taken by a party. They also want to get people's attention on an issue raised. Examples that can be demonstrated are through the history of the world that had once occurred. A Hindu leader named Mahatma Ghandi was willing to sacrifice himself for the benefit of his people by allowing himself to be hungry as a protest from the fighting between two religions that is Islam and Hinduism. He is willing to die of hunger in order to defend his objectives. He is respected by the resident and was considered a leader who is willing to sacrifice himself to the good of people.

\subsubsection{Self-sacrifice}

The method of suicide in this way can be attributed to self-burning. This method is considered ineffective because those who burn themselves need to face a long periods of time to die because $60 \%$ of the human body has water. They need to take at least 10 to 20 minutes to die if the fire is still raging, but if the fire is put out within 10 minutes, they are like roasting themselves. The whole body affected by the fire will burn and hurt so much that some of them cannot stand the heat and cause them to escape from the fire. 
Most people who kill themselves in this way find it hard to die because the fire only burn the skin but the internal organs are still good. This affliction is frightening as the perpetrators have to wait until the deepest layers of the skin and organs burn to die. Those who do this act usually aim to show avoidance of being a victim of atrocities or opposition. This activity is seen as a daring act without war. They are willing to sacrifice themselves with a cruel death to show the opposition. They are willing to sacrifice themselves even though they are considered to be unproductive because they are viewed as sacrifices without laborious effort or better known as losing without fighting. But this method of suicide is considered common thing because it was widely used during the war time to avoid being captured or to be forced to slavery. Now, this method is still being used by those in foreign countries such as Sri Lanka, Guyana, Korea and so on. This act is a short way for them because they are too depressed with the socioeconomic deterioration. Although human-mindedness is fearful of danger and pain, but an urgent situation forces them to act unexpectedly.

\subsubsection{Hanging}

The method of hanging the neck on a rope or cloth is also one of the methods of suicide. By tying the rope around the neck and the rope is connected to a high place like a fan or door. When the neck is suspended and left unattended then one will take less than five to twenty minutes to end their lives. In this condition, their will suffer with shortness of breath because they cannot breathe air and their neck will hurt because of the impact of the straps attached Their tongue will go out and their eyes will be swirling and cause those who cannot stand the torture will take the opportunity to escape because they cannot withstand the pain. This method applies to all countries to punish criminals. When the rope is loosened or pulled out of the neck, they will release a sound even though they have died. The sounds is to release the remaining gases in their bodies. Such cases often involve linking suicide victims due to stress from the problem of love. But this method is no longer foreign to the countries studied above which is the country with the highest rate of suicide in the world. The act of suicide in this way has become a trend by their society because they are accustomed to life depending on their daily needs and the promised hopes of being able to rely on themselves.

\subsubsection{Plunge from high places}

Suicidal methods in this style are extremely risky because many attempts to commit suicide from high altitudes but did not work and have been paralyzed for life. Those who commit this act are selfish because they did not think of what will happen if they do not die but are still alive but are no longer functioning properly. Actors who do this will find hard floors such as cement, iron or stone. When they plunge, the head position should be below but rarely because the lighter head state of the body will cause the head to be in the top position while floating. When a head receives a strong impulse on the floor it is likely that the perpetrator will be easy to die but if the body is hit strongly they may have a chance to live. Many cases occur, even if the perpetrator falls from a high point, they do not die or suffer severe bleeding or broken bones.

\section{Conclusion}

Basically, one's actions to end the life history can lead to a variety of questions that play in mind about the extent to which suicidal action is self-conscious against the state, religion, and society. Every human being has different problems as well as different strengths to prevent such problems. The majority of these suicides are committed by those who face various physical and mental pressures in their daily lives. These people usually act out of the logical mindset without thinking about the bad effects they will face. The phenomenon of this social problem occurs when an individual is too close and affectionate to the people around him, failing to interact with the surrounding community or the community by himself unable to control the actions of an individual resulting in the occurrence of a suicide case. It is very important to assess and keep away from the widespread suicide throughout the country. Precautions can be taken if any problems are resolved thoroughly and guidance is given in full because suicide is an act that is considered irreligious and immoral.

\section{Acknowledgement}

The authors would like to acknowledge the Faculty of Applied Social Science (FSSG) for giving us permission to do this research This research is also supported by FRGS/1/2017/WAB05/ UNISZA/01/1 (RR222) research grant, and thank the East Coast Environmental Research Institute (ESERI), Universiti Sultan Zainal Abidin (UniSZA) for giving advice, guides, support and for the use of their research facilities.

\section{References}

[1] World Health Organization (WHO). (2014). Global Health Estimates: Deaths by cause, age and sex, by country and by region, 2000-2012. WHO.

[2] Langhinrichsen-Rohling, J., Friend, J., \& Powell, A. (2009). Adolescent suicide, gender, and culture: A rate and risk factor analysis. Aggression and Violent Behavior, 14(5), 402-414.

[3] Murphy, G. E. (1998). Why women are less likely than men to commit suicide. Comprehensive Psychiatry, 39(4), 165-175.

[4] Hall, G. S. (1903). The physiology of adolescence. The Youth's Companion, 77, 419

[5] Hawton, K. (2000). Sex and suicide: Gender differences in suicidal behaviour. British Journal of Psychiatry, 177(6), 484-485.

[6] Nock, M. K. (2008). Actions speak louder than words: An elaborated theoretical model of the social functions of self-injury and other harmful behaviors. Applied and Preventive Psychology, 12(4), 159168.

[7] Handelman, L. D., \& Lester, D. (2007). The content of suicide notes from attempters and completers. Crisis, 28(2), 102-104.

[8] World Health Organization (WHO). (2011). WHO report suicidal statistics. WHO.

[9] Ribeiro, J. D., \& Joiner, T. E. (2009). The interpersonal-psychological theory of suicidal behavior: Current status and future directions. Journal of Clinical Psychology, 65(12), 1291-1299.

[10] Sainsbury, P., \& Jenkins, J. S. (1982). The accuracy of officially reported suicide statistics for purposes of epidemiological research. Journal of Epidemiology and Community Health, 36(1), 43 48.

[11] O'Carroll, P. W. (1989). A consideration of the validity and reliability of suicide mortality data. Suicide and Life-Threatening Behavior, 19(1), 1-16.

[12] World Health Organization (WHO). WHO Mortality Database. http://www.who.int/healthinfo/mortality_data/ en/. 